\title{
The Nexus between Consumer Confidence and Economic Growth in South Africa: An ARDL Bounds
} Testing Approach

\author{
Khayelihle Madlopha \\ University of Zululand, Department of Economics, KwaDlangezwa, South Africa \\ khayelihle.madlophah@gmail.com
}

\begin{abstract}
Consumption expenditure contributed a total of $2.2 \%$ to economic growth in 2017. Hence, the South African economy is consumption driven. Therefore, there is a need to understand the growth-economic confidence relationship within the South African context. In this spirit, this paper set to explore the short- and long-run relationship between consumer confidence and economic growth in South Africa for the sample period 1994Q1 to 2017Q4. The method applied, chiefly because our variables were I (0) and I (1) and that we sought short- and long-run estimates were the Autoregressive Distributed Lag (ARDL) model using the bounds testing procedure. The results showed that consumer confidence contributed about $0.025 \%$ to economic growth in the short-run, and about $0.4 \%$ in the long-run. The results suggest that boosting consumer confidence should be keys for South African policy-makers to boost growth in the short- and longrun. In particular, we recommend policy certainty and political stability as some of the ways to attract consumer confidence.
\end{abstract}

Keywords: Consumer confidence, consumption expenditure, economic growth, ARDL, South Africa

\section{Introduction}

South Africa's economic growth has been sluggish and discomforting since the 2008 crisis. The country's economic growth exhibits hysteresis effects ${ }^{1}$ : it has not been able to return to its pre-crisis average level which hovered around $4 \%^{2}$. The slow growth is partly responsible for the high unemployment rate and inequality. Studies (for example, see: Maduku and Kaseeram (2018)) found that economic growth is a determinant of Foreign Direct Investment (FDI) in South Africa, thus suggesting that low growth is also responsible for the downward trend in FDI that the country has been experiencing. Such low growth over years has not been a problem only for the South African economy, but also its citizens (Harmse, 2006). There is thus is an urgent need for the country to set itself on a higher growth path. Amid, the South African government aspires to achieve $5 \%$ growth rate in order to significantly reduce the high unemployment rate and tackle inequality. Consequently, the government has sought many avenues through which to achieve high and sustainable economic growth, with the attraction of FDI the most favoured approach.

However, the yet moderate economic growth evidence that the country has failed to set itself on a higher growth path. This is even after many attempts, specifically economic policies such as the Reconstruction and Development Program (RDP) (1994) and the relatively recent National Development Plan (NDP) (2013). Previous studies which looked at how South Africa can set itself on a higher growth path include Lewis (2001), Faulkner and Loewald (2008), Faulkner, Loewald and Makrelov (2013), Bernstein, de Kadt, Roodt and Schirmer (2014), Nattrass (2014) and Leowald (2018). The weakness of these studies is that they replicated previous studies by using the same variables, notably fiscal, monetary and social (poverty and inequality) variables. Overcoming the weakness of these studies, we contribute ${ }^{3}$ to the existing body of literature on how South Africa can set itself on a higher growth path by introducing a new variable into analysis: consumer confidence 4 .

${ }^{1}$ In Physical Science, 'hysteresis' is the inability of an object to revert to its initial position even after the effects of an external force is removed (Ball and Mankiw, 2002). Contextually, it refers to the inability of South Africa's growth to return to its pre-crisis levels even after the crisis.

${ }^{2}$ The average growth rate was 5\% between 1994 and 2003, and 5\% between 2004 and 2007 (South African Reserve Bank, 2009).

${ }^{3}$ To the best of our knowledge, the relationship between economic confidence and economic growth has not been explicitly studied in South Africa.

${ }^{4}$ Consumer confidence refers to the extent to which households or individual consumers are confident or optimistic about the performance or state of an economy. 
There are chiefly 2 motivations for why consumer confidence is a variable worth incorporating into the analysis of economic growth. Firstly, economic theory justifies the importance of consumer expenditure which is strongly driven by consumer confidence-on economic growth. Keynes (1936) stressed the importance of consumption expenditure on economic growth. He held that higher consumption expenditure led to higher aggregate demand, output and economic growth, which increased labour demand and employment. Thus, it is easy to see the macroeconomic importance of consumption expenditure and, by extension, consumer confidence, in the South African economy. Secondly, consumption expenditure has historically contributed a large portion to annual growth in South Africa, and in 2017 it contributed 2.2\% (Statistics South Africa, 2018), which was the biggest contribution of all expenditure components of Gross Domestic Expenditure (GDE). To that extent, the South African economy is consumption driven and the relationship between consumer confidence and economic growth ought to be examined.

Notwithstanding the importance of this relationship, a few studies have disappointedly explored the relationship between consumer confidence and economic growth (see: Matsusaka \& Sbordone, 1995; Utaka, 2003; Sergeant, 2011; Islam and Mumtaz, 2016). Rather, most studies utilised consumer confidence in predicting consumer expenditure (Leeper, 1992; Howrey, 2001; Ludvigson, 2004) and oil prices (Praet and Vuchelen, 1989; Mehra and Petersen, 2005; Güntner and Linsbauer, 2018), asset pricing (Kim and Oh, 2009; Lemmon \& Portniaguina, 2006; Charoentook, 2005), and stock market analysis (Jansen and Nahuis, 2003; Otoo, 1999; Fisher and Statman, 2003). In this backdrop, this paper aims to explore the short-run and longrun nexus between consumer confidence and economic growth in South Africa. The rest of the paper is set out as follows: Section 2 reviews relevant literature, Section 3 covers data and methodology, Section 4 covers results and analysis, while Section 5 concludes.

\section{Literature Review}

The relationship between economic growth and aggregate spending has a long history in macroeconomics. This relationship attracted macroeconomists after Keynes (1936) wrote the General Theory of Employment, Interest and Money ('The General Theory'). In the wake of the great depression, Keynes (1936) argued that an optimal solution to boost economic activity was to reduce taxes and increase government spending to boost aggregate spending. The rationale was that lowering taxes would spur higher household consumption spending as these economic agents enjoyed higher disposable incomes. As the government spent, it would increase demand for goods and services in the economy and thereby create employment ${ }^{5}$. The culmination of these would be higher economic activity and lower unemployment, thus rescuing the economy from the recession. Attributed to Keynes (1936) is the term 'animal spirits' coined in the General Theory. Put simply, the term referred to the extent to which consumers were determined to consume or purchase goods and services. To the extent that such determination to consume is highly dependent on the confidence of consumers about the future state of the economy (i.e. consumer confidence).

It is clear that consumer confidence entered macroeconomics in earlier years than we think. However, it had not been explicitly coined and studied. Keynesianism proved itself, prominent and successful in many economies, and the importance of consumption expenditure on economic growth was appreciated. This led to attempts directed at measuring economic confidence ${ }^{6}$. These attempts led to the development of consumer confidence index (CCI), which gauges consumer confidence. The CCI has been used to understand the relationship between consumer confidence and various macroeconomic and financial markets variables. As stated before, a few studies have investigated the relationship between consumer confidence and economic growth. On the other hand, most studies investigate consumer confidence in the context of financial markets. One such study is Çelik and Özerkek (2009), who employed a panel cointegration analysis to understand the relationship between consumer confidence, real exchange rate the performance of stock market, interest rates, and personal consumption. The study was in the context of 9 European economies ${ }^{7}$.

\footnotetext{
5 This was summarized by the aggregate consumption function, which represents a positive relationship between aggregate consumption expenditure and output.

${ }^{6}$ Economic confidence is an umbrella term which includes consumer and business confidence, with business confidence measuring the optimism businesses have about an economy.

${ }^{7}$ Denmark, France, Germany, Ireland, Italy, Netherlands, Portugal, Spain, and the United Kingdom
} 
A long-run positive relationship between consumer confidence and the other variables was found. A similar study by Çelik, Aslanoglu and Deniz (2010) was conducted, and a cointegration relationship between consumer confidence and interest rates, exchange rate and the stock market existed. In particular, consumer confidence had a positive effect on these variables. Çelik, Aslanoglu and Uzin (2010) studied the link between consumer confidence and industrial output in 9 emerging economies ${ }^{8}$. Also aided by panel cointegration, the authors also examined how consumer confidence related to the stock market index. Similar to Çelik and Özerkek (2009) and Çelik, Aslanoglu and Deniz (2010), the authors found a positive, long-run impact of consumer confidence on the performance of the stock exchange. Interestingly, the study found a positive impact on consumer confidence of industrial output. This suggests that consumer confidence had positive effects on the economies of these countries, as industrial output is synchronized with economic growth. These results were similar to those of Li (2010), who concluded that consumer confidence Granger-caused industrial output in China.

One of the few studies that examine the relationship between consumer confidence and economic growth, Sergeant, Lugay and Dookie (2011) examined the context of Jamaica and Trinidad and Tobago. The results concurred with those of Oduh, Oduh and Ekeocha (2012), Islam and Mumtaz (2016) and Ibrahim, Bawa, Abdullahi, Didigu and Mainasara (2015), who also found that consumer confidence had a positive and significant impact on economic growth. However, the effect was insignificant for Jamaica. While Çelik et al. (2010) included South Africa in the panel of countries, studying a country as part of a panel has its weaknesses. Panel analysis is weakened by unobserved heterogeneity between countries. After all, no matter how similar or integrated economies are, heterogeneous economic and social structures always present a certain level of unobserved heterogeneity. Also, panel analyses generally omit country-specific policies or optimal policy recommendations. This was also the case with Çelik et al. (2010). Being a single-country analysis, this study addresses the above-mentioned weaknesses of panel analyses.

\section{Data and Methodology}

Data: The sample period was guided by the availability of the unemployment rate data and ranges from 1994Q1 to 2017Q4, with some data interpolated because the real exchange rate, unemployment rate and gross fixed capital were not available on quarterly basis. Given that the sample period starts from the first quarter of the year in which democracy dawned on South Africa, the analysis can be interpreted as the relationship between consumer confidence and economic growth in a democratic society. Our study differs slightly from Islam et al. (2016) by that we use unemployment than employment rate in our analysis, as Statistics South Africa reports the unemployment than the employment rate and unemployment rate statistics make the news frequently and are given more attention in South Africa than employment. The other difference is that we left out real interest rates as a regressor, due to data unavailability. The data for consumer confidence was sourced from the Bureau of Economic Research (BER) and the other data from the South African Reserve Bank (SARB). As a result, Real GDP (G) is used as a dependent variable and independent variables are consumer confidence index (CCI), real effective exchange rate (REER), gross fixed capital formation (GFCF) and unemployment rate (UNE). The real exchange rate and gross fixed capital formation were converted to percentages for analysis purpose. CCI was not logged as it had many negative values.

Method and Model Specification: The empirical method applied in this paper is the Autoregressive Distributed Lag (ARDL) bounds testing procedure proposed by Pesaran, Shin and Smith (2001). There are 3 reasons behind this. Firstly, the model - unlike the Johansen test of cointegration which requires that all variables be I (1) - is applicable in cases similar to the present one, where the data is a mixture of I (0) and I (1) variables (see the discussion on stationary tests below). Secondly, the ARDL model performs better even in the presence of the problem of endogeneity, which is a possible threat to our data as most variables that affect economic growth were parsimoniously omitted. Lastly, with its ability to estimate both short-run and long-run estimates, the model allows us to achieve our objective of examining the relationship between consumer confidence and economic growth in the short- and long-run periods. Diagnostic checks were done, and we found no problem with heteroscedasticity, but with autocorrelation.

${ }^{8}$ Brazil, China, Mexico, Poland, South Africa and Turkey 
The ARDL bounds testing procedure begins with an unconstrained error correction representation:

$$
\begin{gathered}
\Delta \mathrm{Y}_{=} \alpha_{0}+\alpha_{1} \mathrm{Y}_{\mathrm{t}-1}+\alpha_{2} \mathrm{CCI}_{\mathrm{t}-1}+\alpha 3 \text { LREERt }_{-1}+\alpha 4 \mathrm{LGFCFt}_{-1}+\alpha_{5} \mathrm{UNE}_{\mathrm{t}-1} \\
+\sum_{i=1}^{n} \beta_{i} \Delta Y_{t-i}+\sum_{i=1}^{n} \varphi \Delta C C I t_{t-i}+\sum_{i=1}^{n} \theta \Delta L R E R_{t-i}+\sum_{i=1}^{n} \phi \Delta L G F C F_{t-i} \\
+\sum_{i=1}^{n} \delta_{i} \Delta U N E_{t-i} \varepsilon_{\mathrm{t}} \ldots . .(1) \\
\mathrm{t}=1994 \mathrm{Q} 1, \ldots, 2017 \mathrm{Q} 4
\end{gathered}
$$

Where $\Delta$ is the first difference operator, L indicates logarithmic of a variable, and $\varepsilon_{\mathrm{t}}$ the error term. Lag lengths for regressors are automatically selected by Akaike Information Criterion (AIC), as AIC performs better than other alternatives (Lemmon, 2006). In performing the bounds testing procedure, we first estimate equation (1) by the OLS method and then test for the hypothesis of joint significance of lagged level variable parameters using an F-test. The assumption of no trend and intercept is imposed. Pesaran et al. (2001) provide two sets of estimates for the upper and lower bounds to be used in bounds testing. An F-statistic which lies below (upper) the lower bound signals the non- existence (existence) of a long-run relationship, while an F-statistic which lies in between the upper and lower bounds is inconclusive. $\mathbf{H}_{0}: \boldsymbol{\alpha}_{1}=\boldsymbol{\alpha}_{2}=\boldsymbol{\alpha}_{3}=\boldsymbol{\alpha}_{4}=$ $\boldsymbol{\alpha}_{5}=\mathbf{0}$ is the null hypothesis of no long-run relationship, which is tested against the alternative hypothesis $\mathbf{H}_{1}$ : $\alpha_{1} \neq \alpha_{2} \neq \alpha_{3} \neq \alpha_{4} \neq \alpha_{5} \neq 0$.

If a long-run relationship exists, then equation (1) can be represented as an error correction:

$\Delta \log \mathrm{Y}_{\mathrm{t}}=\mathrm{c}+\sum_{i=1}^{n} \beta_{i} \Delta \log Y_{t-i}+\sum_{i=1}^{n} \varphi C C I t_{t-i}+\sum_{i=1}^{n} \theta \Delta R E E R_{t-i}+\sum_{i=1}^{n} \phi \Delta G F C F_{t-i}+\sum_{i=1}^{n} \delta_{i} \Delta U N E_{t-i}+$ $\lambda \mathrm{ECT}_{\mathrm{t}-1}+\varepsilon_{1 \mathrm{t}} \ldots . .(2)$

Where, lagged by one quarter, $\mathrm{ECT}_{\mathrm{t}-1}$ is an error correction term that corrects short-run disequilibria to achieve a long-run equilibrium.

\section{Results and Discussion}

As stated before, if the bounds test indicates a cointegrating relationship, then it suggests the existence of a long-run relationship between variables of interests. In this Section, we therefore first present results of the

\begin{tabular}{|c|c|c|c|c|c|c|c|}
\hline \multirow[t]{2}{*}{ F statistic } & \multirow{2}{*}{\multicolumn{2}{|c|}{$\begin{array}{l}5 \% \text { critical value } \\
\text { Bound }\end{array}$}} & \multicolumn{3}{|c|}{$\begin{array}{l}1 \% \text { critical value } \\
\text { bounds }\end{array}$} & \multicolumn{2}{|c|}{ Conclusion } \\
\hline & & & I $(0)$ & $\mathrm{I}(1)$ & & $\mathrm{I}(0)$ & I (1) \\
\hline $\mathbf{F}_{\mathbf{g}}=3.852452$ & 2.69 & 3.83 & & 3.31 & 4.63 & & ntegrated \\
\hline
\end{tabular}
bounds test and follow with short-run and long-run estimates.

Bounds Testing: The following results were obtained, where $\mathbf{F}_{\mathbf{g}}$ indicates the F-statistic obtained when growth was a dependent variable.

$\mathrm{F}_{\mathrm{g}}$ is above the upper bound at $5 \%$, thus evidencing that a long-run relationship exists at $5 \%$ level of significance.

Short-Run Estimates: To obtain short-run estimates, we estimated an OLS model. After checking stationarity using the Philipps-Peron test, all variables were differed once to satisfy stationarity, except for consumer confidence, which was I (0). Diagnostic checks were done, and we found no problem with heteroscedasticity, but with autocorrelation. To correct for autocorrelation, we added a one-quarter lag of the dependent as a regressor. After this, autocorrelation was corrected for. For reasons outlined in the next subsection, 3 dummy variables were incorporated in the model. The data was normality distributed, according to the Jacque-Bera test. The Ramsey RESET Test indicated no model misspecification. 
Table 1: Short-Run Estimates

\begin{tabular}{|c|c|c|c|c|}
\hline Variable & Coefficient & Std. Error & t-Statistic & Prob. \\
\hline $\mathrm{C}$ & 0.001973 & 0.001269 & 1.554342 & 0.1238 \\
\hline DUNE & -0.000560 & 0.000617 & -0.908476 & 0.3662 \\
\hline DLGFCF & 0.037336 & 0.014165 & 2.635777 & 0.0100 \\
\hline DLREER & -0.010388 & 0.011717 & -0.886506 & 0.3778 \\
\hline $\mathrm{CCI}$ & 0.000225 & $6.43 \mathrm{E}-05$ & 3.492290 & 0.0008 \\
\hline DIT & 0.005068 & 0.001742 & 2.909170 & 0.0046 \\
\hline DCRISIS & -0.003902 & 0.001689 & -2.310414 & 0.0233 \\
\hline DGFR & 0.000725 & 0.001417 & 0.511812 & 0.6101 \\
\hline DG(-1) & 0.281638 & 0.097949 & 2.875366 & 0.0051 \\
\hline R-squared & 0.438593 & \multicolumn{2}{|c|}{ Mean dependent var } & 0.007077 \\
\hline Adjusted R-squared & 0.385754 & \multicolumn{2}{|c|}{ S.D. dependent var } & 0.005821 \\
\hline S.E. of regression & 0.004562 & \multicolumn{2}{|c|}{ Akaike info criterion } & -7.851346 \\
\hline Sum squared resid & 0.001769 & \multicolumn{2}{|c|}{ Schwarz criterion } & -7.607839 \\
\hline Log-likelihood & 378.0133 & \multicolumn{2}{|c|}{ Hannan-Quinn criteria. } & -7.752987 \\
\hline F-statistic & 8.300656 & \multirow{2}{*}{\multicolumn{2}{|c|}{ Durbin-Watson stat }} & 1.970327 \\
\hline Prob(F-statistic) & 0.000000 & & & \\
\hline
\end{tabular}

As reported in Table 1 above, consumer confidence contributes about $0.0225 \%$ to economic growth in the short-run. The results concur with results reported by Sergeant et al. (2011), Oduh et al. (2012), Ibrahim et al. (2015) and Islam and Mumtaz (2016), who find a positive effect of consumer confidence on economic growth. The announcement of the inflation targeting regime boded well for short-run growth, with an increase of $0.5 \%$ in growth. This was through expectations of a more effectively managed inflation, which was good for forecasting and real returns for investors. A one percentage-point increase in fixed investment was associated with a $0.03 \%$ increase in short-run growth. This possibly happened through the channel of increased shortrun employment. Growth in the previous quarter contributed $0.28 \%$ to growth in the current period. Unemployment was insignificant in explaining short-run growth, and the aftermath of the $2008 / 2009$ crisis, 2000s crisis and exchange rate were found to have no impact on economic growth in the short-run.

Long-Run Estimates: We employed the Error Correction Model to estimate the long-run estimate. However, the error correction term was positive. We suspected some issues with the model and did checks on possible sources of the issues. Initially, we had excluded the trend in the model. After including the trend in the model, it was significant, thus signalling that it should be included in the model. Yet, the error correction term was positive. We did further checks and tested for structural breaks using the Multiple Breakpoint Test. The results indicated that in 1999q1, 2003q4 and 2010q1 there were breaks or changes in the structures. We assert that the 1999q1 break is attributed to expectations of the change in monetary policy regime; that is, introduction of the formal inflation targeting. We believe the '2000s recessions' - which affected the European Union between 2000 and 2001 and the US between 2002 and 2003 - had spill-over effects to South Africa, as the US and European Union had relatively heavier ties with South Africa. We attribute the 2010q1 break to the aftermath of the great financial crisis. To incorporate the breaks in the model, we added dummy variables for these break periods. $\mathbf{D}_{\mathbf{i t}}, \mathbf{D}_{\text {crisis }}$ and $\mathbf{D}_{\text {gfr }}$ are for the respective periods and breaks discussed 0 for the periods before breaks and 1 after. After this, the error correction term had the expected sign and magnitude and was significant. The model was dynamically stable, with the Ramsey RESET Test indicating no model misspecification. We found that about $16 \%$ of short-run disequilibrium is corrected within one quarter. This signifies a moderate adjustment to the steady-state. Given the significance of the speed of adjustment, however, we welcome the results. 
Table 2: Long-Run Estimates

\begin{tabular}{|c|c|c|c|c|}
\hline \multicolumn{5}{|c|}{ Cointegrating Form } \\
\hline Variable & Coefficient & Std. Error & t-Statistic & Prob. \\
\hline $\mathrm{D}(\mathrm{G}(-1))$ & 0.164561 & 0.105901 & 1.553912 & 0.1244 \\
\hline $\mathrm{D}(\mathrm{CCI})$ & 0.000198 & 0.000072 & 2.735979 & 0.0077 \\
\hline $\mathrm{D}(\mathrm{CCI}(-1))$ & -0.000097 & 0.000089 & -1.081644 & 0.2828 \\
\hline $\mathrm{D}(\mathrm{CCI}(-2))$ & -0.000144 & 0.000077 & -1.870472 & 0.0653 \\
\hline D(LREER) & -0.021809 & 0.008779 & -2.484183 & 0.0152 \\
\hline D(LGFCF) & 0.042301 & 0.019013 & 2.224842 & 0.0291 \\
\hline $\mathrm{D}(\mathrm{UNE})$ & 0.000198 & 0.000405 & 0.490375 & 0.6253 \\
\hline D(DCRISIS) & -0.002296 & 0.002107 & -1.089729 & 0.2793 \\
\hline D(DCRISIS(-1)) & 0.006386 & 0.001899 & 3.361805 & 0.0012 \\
\hline D(DIT) & 0.009023 & 0.002194 & 4.112828 & 0.0001 \\
\hline D(DGFR) & 0.004756 & 0.002137 & 2.225412 & 0.0290 \\
\hline D(@TRENDO) & 0.000780 & 0.000212 & 3.682516 & 0.0004 \\
\hline CointEq(-1) & -0.158512 & 0.042766 & -3.706466 & 0.0004 \\
\hline \multicolumn{5}{|c|}{$\begin{array}{l}\text { Cointeq }=\text { G }-(0.0036 * \text { CCI }-0.1376 * \text { LREER }+0.0825 * \text { LGFCF }+0.0013 * \text { UNE } \\
\quad+0.0363 * \text { DCRISIS }+0.0569 * \text { DIT }+0.0300 * \text { DGFR }+13.9151+0.0049 \\
\quad \text { @@TREND })\end{array}$} \\
\hline \multicolumn{5}{|c|}{ Long Run Coefficients } \\
\hline Variable & Coefficient & Std. Error & t-Statistic & Prob. \\
\hline CCI & 0.003597 & 0.001004 & 3.581515 & 0.0006 \\
\hline LREER & -0.137589 & 0.053498 & -2.571854 & 0.0121 \\
\hline LGFCF & 0.082516 & 0.092013 & 0.896784 & 0.3727 \\
\hline UNE & 0.001252 & 0.002505 & 0.499601 & 0.6188 \\
\hline DCRISIS & 0.036324 & 0.025603 & 1.418733 & 0.1601 \\
\hline DIT & 0.056923 & 0.018042 & 3.155008 & 0.0023 \\
\hline DGFR & 0.030006 & 0.013998 & 2.143531 & 0.0353 \\
\hline $\mathrm{C}$ & 13.915095 & 1.172679 & 11.866075 & 0.0000 \\
\hline @TREND & 0.004921 & 0.000972 & 5.064729 & 0.0000 \\
\hline
\end{tabular}

The results, as reported in Table 2, suggested that, in the long-run, consumer confidence had a significant effect on economic growth. Specifically, a one unit increase in consumer confidence is associated with a $0.4 \%$ increase in long-term growth rate, showing that an increase in consumer confidence boosts economic growth both in the short-run and long-run periods. The findings are similar to those presented by Çelik et al. (2010), Li (2010), Sergeant et al. (2011) and Ibrahim et al. (2015). The exchange rate appreciation in the long-run hampers growth by about $13.8 \%$. This implies that, as expected, sustained exchange rate appreciations contribute to a lower growth rate. An obvious channel through which sustained exchange rate appreciations affect growth is a decline in exports. The adoption of the inflation targeting framework contributed positively $(5.7 \%)$ to long-term. This fed through expectations, as inflation targeting was expected to have positive impacts on the economy. The unemployment rate, gross fixed capital formation, aftermath of the 2008/2009 crisis and the 2000s crisis were found insignificant in explaining long-term growth.

\section{Concluding Remarks}

In this paper, we analyzed the relationship between consumer confidence and economic growth in the shortrun and long-run periods with the help of ARDL bounds testing procedure. For both periods, an increase in consumer confidence was associated with a positive and significant increase in economic growth, affirming 
our earlier argument that consumer confidence is important for South Africa's economy. From this, we suggest that South African policy-makers consider ways in which they can increase consumer confidence and thus enhance economic growth. In particular, we propose policy certainty and political stability as some of the ways in which consumer confidence can be boosted.

\section{References}

Ball, L. \& Mankiw, N. G. (2002). The NAIRU in Theory and Practice. Journal of Economic Perspectives, 16(4), 115-136.

Bernstein, A., de Kadt, J., Roodt, M. \& Schirmer, S. (2014). South Africa and the Pursuit of Inclusive Growth, Johannesburg: Centre for Development and Enterprise (CDE) and Legatum Institute.

Çelik, S. \& Özerkek, Y. (2009). Panel Cointegration Analysis of Consumer Confidence and Personal Consumption in the European Union. Journal of Business Economics and Management, 10(2), 161-168.

Çelik, S., Aslanoglu, E. \& Uzun, S. (2010). Determinants of Consumer Confidence in Emerging Economies: A Panel Cointegration Analysis. 30th Annual Meeting of the Middle East Economic Association. Atlanta, GA, Allied Social Science Associations.

Çelik, S., Aslanoglu, E. \& Deniz, P. (2010). The Relationship between Consumer Confidence and Financial Market Variables in Turkey during the Global Crisis. 30th Annual Meeting of the Middle East Economic Association. Atlanta, GA, Allied Social Science Associations.

Charoentook, A. (2005). Does Sentiment Matter. Working Paper, Vanderbilt.

Faulkner, D. \& Leowald, C. (2008). Policy Change and Economic Growth: A Case Study of South Africa, Washington: The International Bank for Reconstruction and Development / The World Bank.

Faulkner, D., Leowald, C. \& Makrelov, K. (2013). Achieving higher growth and employment: Policy Options for South Africa, Pretoria: Economic Research Southern Africa (ERSA).

Fisher, K. \& Statman, M. (2003). Consumer Confidence and Stock Returns. Journal of Portfolio Management, $30(1), 115-127$.

Gutner, J. H. F. \& Linsbauer, K. (2018). The Effects of Oil Supply and Demand Shocks on U.S. Consumer Sentiment. Journal of Money, Credit and Banking, 50(7), 1617-1644.

Harmse, C. (2006). The relationship between South Africa's macroeconomic policies and the performance of the various asset classes.

Howrey, E. P. (2001). The Predictive Power of the Index of Consumer Sentiment. Brookings Papers on Economic Activity, Economic Studies Program. Washington D.C.: The Brookings Institution.

Ibrahim, A. et al. (2015.) Consumer Confidence Indicators and Economic Fluctuations in Nigeria. Journal of Applied Statistics, 6(1), 285-300.

Islam, T. U. \& Mumtaz, M. N. (2016). Consumer Confidence Index and Economic Growth: An Empirical Analysis of EU Countries. EuroEconomica, 35(2), 17-22.

Jansen, W. \& Nahuis, N. (2003). The stock market and consumer confidence: European evidence. Economics Letters, 79, 89-98.

Keynes, J. M. (1936). The General Theory of Employment, Interest and Money. London: Macmillan.

Kim, S. N. \& Oh, W. (2009). Relationship between Consumer Sentiment and Stock Price in Korea. The Journal of the Korean Economy, 10(3), 421-442.

Leeper, E. M. (1992). Consumer Attitudes: King for a Day, Atlanta: Federal Reserve of Atlanta: Economic Review.

Lemmon, M. \& Portniaguina, E. (2006). Consumer Confidence and Asset Prices: Some Empirical Evidence. The Review of Financial Studies, 19(4), 1499-1529.

Leowald, C. (2018). South African Macroeconomics and Growth. The Journal of Helen Suzman Foundation, 82, 15-20.

Lewis, J. D. (2001). Policies to Promote Growth and Employment in South Africa. Misty Hills, Muldersdrift, The World Bank Southern Africa Department.

Li, C. (2010). Does Consumer Confidence Forecast Economic Fluctuations? The Case of China. Institute of Economics, Chinese Academy of Social Sciences.

Ludvigson, S. C. (2004). Consumer Confidence and Consumer Spending. Journal of Economic Perspectives, 18(2), 29-50.

Maduku, H. \& Kaseeram, I. (2018). Inflation Targeting Monetary Policy and Unemployment in South Africa. Journal of Economics and Behavioral Studies, 10(4), 88-96. 
Matsuaka, J. G. \& Sbordone, A. M. (1995). Economic Inquiry, 33(2), 296-318.

Mehra, Y. P. \& Petersen, J. (2005). Oil Prices and Consumer Spending. FRB Economic Quarterly, 91(3), 53-72.

Nattrass, N. (2014). South Africa: Post-Apartheid Democracy and Growth. Johannesburg, Centre for Development and Enterprise (CDE).

Oduh, M., Oduh, M. O. \& Ekeocha, P. C. (2012). The Impact of Consumer Confidence and Expectation on Consumption in Nigeria:Evidence from Panel Data. European Journal of Business and Management, 9(4), 86-100.

Otoo, M. (1999). Consumer Sentiment and the Stock Market. Finance and Economics Discussion Paper, Federal Reserve Board.

Pesaran, M. H., Shin, Y. \& Smith, R. J. (2001). Bounds testing approaches to the analysis of level relationships. Journal of Applied Econometrics, 16(3), 289-326.

Praet, P. \& Vuchelen, J. (1989). Exogenous shocks and consumer confidence in four major European countries. Applied Econometrics, 20(2), 561-567.

Sergeant, K., Lugay, B. \& Dookie, M. (2011). Consumer Confidence and Economic Growth- A Case Study of Trinidad \& Tobago. Trinidad, Halton Trinidad \& Conference Center Port of Spain.

South African Reserve Bank. (2009). The South African Reserve Bank Quarterly Bulletins, Pretoria: South African Reserve Bank.

Statistics South Africa. (2018). Statistical Release: Gross Domestic Product, Fourth Quarter 2017, Pretoria: Statistics South Africa.

Utaka, A. (2003). Confidence and the real economy - the Japanese case. Applied Economics, 35(3), 337-342. 